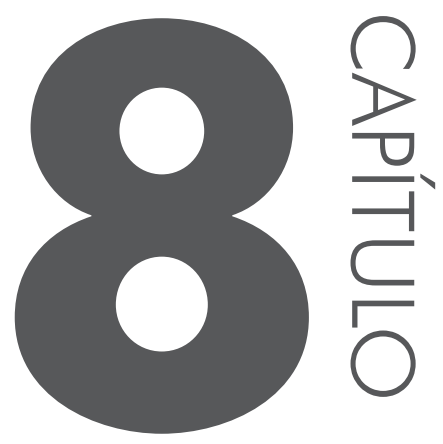

\title{
ECONOMIA DE COMUNHÃO: UM ESTUDO NA PERSPECTIVA DE RETOMADA DO DEBATE ÉTICO NA ECONOMIA
}

Francisco Rafael Félix de Sousa ${ }^{1}$ Pedro Ferreira Barros ${ }^{2}$

\subsection{INTRODUC̣ÃO}

O desenvolvimento capitalista enfrenta crises na atualidade por tratar-se de um sistema que tem por base o aumento constante da rentabilidade econômica e da competitividade nos mercados, desprezando os aspectos sociais. A organiza-

1 Bacharel em Ciências Econômicas pela Universidade Regional do Cariri (URCA). Contato: rafa. sal.jesus@hotmail.com, (88) 88236507.

2 Professor Adjunto do Departamento de Economia da Universidade Regional do Cariri (URCA). Mestre em Sociologia e doutor em Educação pela Universidade Federal do Ceará (UFC). Contato: pf_barros@ymail.com, (88) 3511-3610. 
ção democrática da sociedade faz surgir também movimentos sociais e políticos que entram em contradição com os princípios utilitarista e individualista provenientes do capitalismo. Por razões de necessidade, iniciativas alternativas de organização do trabalho ou de gestão visam a garantir a subsistência e melhor qualidade de vida às pessoas afetadas pelos rumos que foram tomados pelas nações das quais fazem parte.

Dentre as propostas alternativas, a Economia de Comunhão, ou, como é mais popularmente chamada, EdC, surge com a finalidade principal de luta contra a miséria como um meio para construção de um mundo mais justo e mais fraterno, objetivando contribuir para a edificação de um sistema econômico e de uma sociedade de comunhão sob a inspiração dos princípios cristãos. Estes princípios são defendidos por um movimento ligado à Igreja Católica conhecido como Movimento dos Focolares $^{3}(\mathrm{MF})$. Os folcolares se constituem em um movimento ecumênico, de inspiração cristã, aberto ao diálogo e à parceria com aqueles que, mesmo não professando uma fé, querem construir a unidade, o Mundo Unido, a fraternidade universal.

Para autores como Sen (1999) a economia nasce de duas vertentes: a engenharia e a ética. Em busca de uma ciência mais "neutra", as Ciências Econômicas foram esquecendo cada vez mais a segunda vertente como se a omissão dos valores extinguisse a sua existência. Já a Economia de Comunhão surge embasada em uma proposta espiritual, podendo ser considerada como uma proposta que privilegia a questão dos valores e da ética nas escolhas econômicas.

Os sujeitos produtivos da EdC são empresários, trabalhadores, até mesmo clientes e fornecedores, e demais agentes empresariais, que buscam inspiração em princípios fundamentados em uma cultura diferente da prática e da teoria econômica vigente. Essa cultura pode ser definida como "cultura do dar" em antítese a "cultura do ter".

O dar econômico é a expressão do "dar-se" no sentido de "ser". Em outras palavras, revela uma concepção antropológica que não é individualista e nem coletivista, mas de comunhão. A "cultura do dar" não se confunde com filantropia nem com assistencialismo, ambas, virtudes da abordagem individualista.

Considerando que a essência da pessoa é estar em comunhão, a EdC se caracteriza como cultura de comunhão. As empresas são a espinha dorsal do projeto. Estas são empresas inseridas no mercado, que adotam as formas jurídicas comuns, mas que, por decisão livre dos seus titulares, se propõem destinar os seus lucros de acordo com critérios ditados pelo bem comum.

3 Movimento dos Focolares (do italiano: focolare = fogo-lareira, lar). 
Bruni (2011b) argumenta que essa nova cultura de comunhão é para ser uma nova ordem econômico-social que repensa e liga duas realidades hoje opostas no capitalismo: a empresa e a pobreza. Nesse sentido, uma economia que mostra o perfil da comunhão e, portanto, uma economia com perfil realmente humano.

Assim, diante dessa nova economia, nos propomos a este estudo, buscando compreender a sua forma de inserção entre as abordagens teóricas das Ciências Econômicas, relevando a sua vertente ética. Posto isso, procuramos estudar a fundamentação dessa proposta, princípios ético-filosóficos e fundamentos social e econômico, bem como o contexto de seu surgimento, com o intuito de apreender a EdC enquanto práxis e retomada do debate ético na economia.

\subsection{UMA QUESTÃO PARA A ATUALIDADE}

O sistema econômico vigente, orientado cada vez mais para a produção de riquezas, tem sido apresentado como produtor e reprodutor da desigualdade social. A pobreza e a miséria são, portanto, consequências da concentração da riqueza nas mãos de alguns, enquanto a maioria não consegue satisfazer adequadamente suas necessidades básicas. Nesse sentido, a pobreza está para além da insuficiência de renda e engloba outros aspectos, como a falta de acesso aos alimentos, à moradia, à proteção, à saúde e à educação.

Os desequilíbrios da concentração de renda entre países e entre classes sociais, principalmente nos países periféricos, permanecem como um dos grandes problemas da atualidade. As instituições econômicas, sociais, políticas e culturais que foram concebidas nesse sistema reproduzem a desigualdade social e muitas vezes se amparam em um arcabouço teórico-econômico, trazendo modelos de desenvolvimento que reduzem a complexidade das escolhas econômicas, desconsiderando o debate ético.

Também o processo de globalização nesse contexto capitalista que o mundo vem vivenciando faz com que os mercados se tornem altamente competitivos de forma que podem comprometer a sobrevivência de produtores pequenos que não possuem capitais suficientes para manter-se. Segundo Sposati (1997), o processo de globalização dos mercados consiste na disseminação de ideias neoliberais que têm, entre outros objetivos, o da unificação do capital. O processo de globalização tem acarretado sérios problemas sociais e econômicos, principalmente para os países que buscam o desenvolvimento como é o caso do Brasil.

No Brasil as consequências desse novo paradigma já podem ser notadas. Trata-se dos vários desempregados que o país possui. Eles estão desempregados porque não tiveram oportunidade de se inserir no mercado de trabalho ou foram expulsos deste por não terem a capacitação desejada. Esses são alguns dos 
entraves para o desenvolvimento que, segundo Bertucci et al. (2010), está em crise. Afirmam eles:

A expansão da atual concepção de desenvolvimento, compreendido como crescimento econômico se tem inicio, a partir da metade do século XX, após a Segunda Guerra Mundial, quando foi criado um clima favorável ao chamado "desenvolvimentismo", cujo carro-chefe era formado pela industrialização e urbanização. O crescimento da economia, medido pelo aumento da produtividade e da produção de riquezas, pela ampliação da capacidade de consumo nas cidades e pela modernização tecnológica, na produção e nos bens de consumo, virou sinônimo de desenvolvimento (BERTUCCI et al., 2010, p. 11).

No entanto, os indicadores econômicos e sociais marcam as fronteiras da pobreza e da riqueza entre continentes, países e suas populações. Os modelos de desenvolvimento capitalista hoje enfrentam crises, pois se trata de modelos que têm por base o aumento constante da rentabilidade econômica e da competitividade nos mercados, desprezando os aspectos sociais e fragmentando a relação economia-sociedade. ${ }^{4}$ Sendo assim, os debates teóricos e políticos em torno da dialética econômico-social se subdividem

em dois "partidos": os que concebem o campo econômico e os mercados, como construtores do campo social, e os que, ao contrário, consideram o campo econômico em conflito endêmico com o social. A tradição da economia política liberal está incluída no primeiro partido, enquanto a tradição sociológica no segundo. Os teóricos da economia liberal (desde Adam Smith, no passado, a Amartya Sen, na atualidade) consideram o mercado expressão da sociedade civil; o desenvolvimento econômico, indicador do desenvolvimento social; a liberdade econômica, pré-requisito de outras liberdades. [...] No lado oposto a essa primeira tradição, encontramos autores que consideram os campos econômico e social realidades conflitantes entre si. Essa tradição, que conta entre seus expoentes autores muito diferentes entre si, como Marx e Polanyi, Weber e Simmel, considera a esfera econômica regida por princípios substancialmente em conflito com os princípios que regem a esfera social (BRUNI, 2011a, p. 16-17).

Em diversos países, em períodos iguais ou distintos, na maioria dos casos, por razões de necessidade, iniciativas alternativas de organização do trabalho ou de ges-

4 A visão da relação economia-sociedade típica da Economia de Comunhão (EdC) alinha-se com a tradição da chamada economia civil, tradição essa que aprofunda suas raízes no pensamento clássico, no período medieval cristão e no humanismo civil italiano (especialmente na escola napolitana do século XVIII, de AntonioGenovesi) e age, por conseguinte, a partir de uma perspectiva radicalmente diferentedas duas visões hoje predominantes. A ideia central é olhar a experiência da sociabilidade humana e da reciprocidade dentro da vida econômica normal; nem a lado, nem antes nem depois. Ela afirma que os princípios outros, que não o lucro e a troca instrumental, podem - querendo - encontrar espaço dentro da atividade econômica. 
tão procuram garantir a subsistência e melhor qualidade de vida às pessoas negativamente afetadas pelos rumos que foram tomando as nações de que fazem parte.

Com isso é possível pensar em outras possibilidades de organização da economia que não seja orientada pela ganância, pela sede de lucros que vão sendo acumulados e geram desigualdade. Ainda segundo Bruni (2002, p. 47),

Muito embora o individualismo da ciência econômica tenha sobrevivido e saído fortalecido de todo gênero de crítica, um número sempre crescente de economistas está insatisfeito com essa orientação da teoria econômica predominante, porque houve uma tomada de consciência do fato que ter expulsado da economia a dimensão relacional impede a compreensão de muitas realidades e comportamentos econômicos.

É possível, então, repensar a economia a partir de outros valores - da justiça, da igualdade, da solidariedade. E esse não é só um convite de grupos de cristãos católicos, por exemplo, mas algo que vem sendo defendido por autores das Ciências Econômicas, como Amartya Sen (1999). A economia, assim, pode ser também geradora de igualdades, desde que seja orientada pela justiça social, que significa a partilha justa dos bens e recursos que possam satisfazer as necessidades de todos e não apenas de alguns.

A economia pode ser uma alternativa de geração de emprego e renda para as pessoas que acreditarem neste novo modo de vê-la. Diante de um mercado globalizado, altamente competitivo e individualista surge uma economia que coloca o homem no centro do processo, constituindo unidades produtivas alicerçadas na comunhão e na solidariedade.

É nesse cenário que se apresenta a EdC: ela tenciona promover uma visão do agir econômico como compromisso para a promoção integral das pessoas e da sociedade, por meio de ações e comportamentos inspirados na fraternidade. A EdC é uma variante da Economia Social e da Economia Solidária. É um movimento que promove alternativas às tradicionais relações econômicas, considerando a pessoa e o seu crescimento no centro da economia.

A EdC é uma proposta de geração de riqueza dentro do sistema capitalista. Ainda não é amplamente conhecida por todos: no entanto, para aqueles que têm contato com ela, ocorre uma curiosidade e uma admiração por esta via que prevê um modo mais justo e fraterno de ampliação da oferta de bens e serviços. Desde o seu nascimento, em 1991, por ocasião de uma visita a São Paulo pela sua idealizadora Chiara Lubich, esta nova economia tem aumentado o número de adeptos (empresários, empresas, associações, instituições econômicas, intelectuais, estudantes, trabalhadores, consumidores, simpatizantes, pobres, ricos e muitos outros). Mas como surgiu essa novidade? Que ideal motivou esse novo jeito de ver e fazer a economia? 
A seguir, apresentaremos de forma um tanto breve a gênese e o desenvolvimento da proposta da EdC, procurando fazer esta identificação descritiva sem descuidar de conferir ao relato o necessário aprofundamento para que o leitor possa compreender a sua essência como uma nova cultura econômica.

\subsection{ECONOMIA DE COMUNHÃO: HISTÓRIA E PROFECIA}

A EdC é fruto da inspiração da sua fundadora Chiara Lubich (1920-2008), uma italiana idealizadora de um carisma, o Movimento dos Focolares (MF), que nasceu em Trento, na Itália, em 1943, em meio à Segunda Guerra Mundial. Em reuniões à beira de fogueiras com suas amigas adolescentes em um cenário de destruição provocado por bombardeios, Chiara teve a intuição "sobre quem é verdadeiramente Deus: é Amor" (LUBICH, 2000, p. 37). Diante dessa intuição ela assumiu que, postas em prática, as palavras do Evangelho provocariam uma revolução.

Ali mesmo começaram a fazer o que podiam. Preocupavam-se em ajudar o próximo, encontrando refúgio para os desabrigados, alimentos para quem tinha fome, preocupando-se sempre com os mais necessitados, fazendo comunhão de bens a fim de minimizar os efeitos sobre as pessoas das consequências da guerra.

Assim, é possível perceber claramente na origem do Movimento dos Focolares seu cunho religioso e social. Em 1962 o Movimento foi aprovado pela Igreja Católica, ${ }^{5}$ com o nome oficial de Obra de Maria e em 1967 já era responsável por mil obras sociais no mundo. Apesar de ser um movimento católico, participam dele pessoas de diversas denominações, inclusive pessoas sem vínculos religiosos, mas todas ligadas ao propósito de construir um mundo unido e fraterno. Assim o diálogo interreligioso também é um traço fundamental do movimento. No Movimento existem pessoas das mais diversas crenças e convicções. Há judeus, muçulmanos, budistas, hinduístas, ortodoxos e muitos outros que resolveram viver essa cultura da partilha e da unidade. Há também pessoas sem convicção religiosa, os chamados ateus, que lutam junto ao movimento por um mundo de mais solidariedade, justiça e paz.

Espalhando-se pelo mundo, o MF chegou ao Brasil, em 1958. Já no ano seguinte dois centros de formação foram abertos no Recife e logo o movimento se espalhou por todo o país. Atualmente no Brasil há em torno de 55 bases do Movimento, estando ele presente em quase todas as capitais brasileiras. A sede do movimento no Brasil fica em São Paulo, na cidade-modelo (ou cidade-testemunho)

5 Em 1962 acontece a primeira aprovação pontifícia ad experimentum. O papa João XXIII reconhece o Movimento com o nome de Obra de Maria. Disponível em: <http://www.focolare.org/ pt/movimento-dei-focolari/storia/>. Acesso em: 27 maio 2013. 
Mariápolis Ginetta, ${ }^{6}$ na região de Vargem Grande Paulista, no estado de São Paulo. Há ainda outras duas Mariápolis no País, a Mariápolis Glória em Benevides, no Pará e a Mariápolis Santa Maria em Igarassu, em Pernambuco. Hoje, de acordo com o site oficial, o Movimento conta com mais de 2,2 milhões de adeptos entre membros e simpatizantes espalhados por 182 países em todo o mundo.

O MF possui uma estreita ligação com o social. Frequentemente o movimento se reúne para discutir assuntos ligados ao social com o intuito de fazer brotar novas ideias para tentar minimizar as barreiras sociais. Surgidas nessa área, existem pessoas das mais diversas profissões as quais colocam suas capacidades intelectuais a serviço da organização e de todos, afinal, o objetivo principal dos Focolares é divulgar a partilha em todas as suas dimensões. Com isso, sociólogos, economistas, empresários e muitos outros profissionais discutem questões e apresentam ideias para solução de problemas mundiais e locais.

No campo econômico, o grande projeto deste Movimento é sem dúvida a Economia de Comunhão. Uma iniciativa desafiadora diante da realidade econômica do Brasil e do mundo. A EdC, versão empresarial e econômica do Movimento, surgiu no Brasil em 1991. A ideia central é a criação de empresas dirigidas por pessoas éticas, honestas e competentes, que se disponham livremente a partilhar parte dos lucros a serviço do bem comum.

É interessante saber, de forma mais precisa, como brota a ideia de EdC. A esse respeito Chiara Lubich narra que enquanto atravessava a cidade de São Paulo para chegar à comunidade do movimento, foi vendo de um lado prédios imensos e luxuosos e, do outro, um subúrbio e uma pobreza alarmante.

Aqui existe carência, sobretudo de amor verdadeiro e autêntico, especialmente se pensarmos na "coroa e espinhos" (como o cardeal de São Paulo, D. Evaristo Arns, fala do cinturão de pobreza e miséria da periferia), coroa que circunda a cidade repleta de arranha-céus. É o grande problema destas terras em via de desenvolvimento, um dos maiores problemas de nosso Planeta, pelo qual nós poderemos fazer muito pouco. Mas Deus Pai pode cuidar da solução. E também pela nossa fé de filhos seus (LUBICH, 1991 apud QUARTANA, 1992, p. 15).

Isso fez com que ela pensasse em como o movimento poderia ajudar para minimizar e, quem sabe, extinguir essa desigualdade no Brasil e no mundo.

6 As cidades-testemunho - Mariápolis permanentes - do Movimento dos Focolares são "laboratórios de uma pequena cidade", cuja lei fundamental é o Mandamento Novo de Jesus, o amor mútuo vivido entre todos. Elas contêm todas as expressões da vida: trabalho, estudo, oração etc. Desejam ser o esboço de uma "sociedade nova", totalmente renovada pelo evangelho. Hoje existem trinta e três delas nos cinco continentes. 
Recorremos ao relato de Quartana (1992) para conhecer o pensamento de Chiara a fim de saber como se dá a inspiração para idealizar a Economia de Comunhão:

Em 1900 São Paulo era uma cidade pequena. Agora é uma Floresta de arranha-céus. É grande o poder do capital nas mãos de alguns e tamanha é a exploração dos outros. E pergunto: mas por que este poderio todo não se orienta para a solução dos imensos problemas do Brasil? Porque falta amor ao irmão; o que domina é o interesse, o egoísmo [...]. Que caricatura é o mundo sem Jesus (LUBICH, 1991 apud QUARTANA, 1992, p. 15).

Diante da conjuntura de pobreza, que naquela época já assolava o cenário mundial, e motivada pela cena de enorme desigualdade social presenciada de modo pessoal e especifico em São Paulo, a italiana Chiara Lubich, inconformada, decidiu lançar um projeto com o objetivo de colaborar para a diminuição das desigualdades sociais e a erradicação da miséria. Esse projeto denominado Economia de Comunhão foi lançado em 29 de maio de 1991 na sede do Movimento no Brasil, em São Paulo.

Compreende-se que esse projeto tenha nascido justamente no Brasil devido às desigualdades que este país possui. A conjuntura econômico-social que sofria e sofre ainda hoje com uma intensa desigualdade social, tendo muito poucos ricos e milhares ou até milhões de pessoas muito pobres, corroborou a criação da EdC. O projeto Economia de Comunhão na Liberdade, ${ }^{7}$ como também ficou conhecido inicialmente, consistiu na ideia de criar uma rede social que envolve essas empresas que destinassem parte do lucro aos pobres, relacionando a atividade econômica à promoção da fraternidade entre os homens.

A inspiração da italiana é então objetivada na forma de intervenção econômica por meio da criação e do gerenciamento de empresas também capitalistas, mas diferenciadas daquelas já existentes movidas exclusivamente pela ambição do lucro. Chiara Lubich propunha algo viável economicamente e não um estilo de produção utópica, conforme afirma:

Embora eu não seja especialista em problemas econômicos, pensei que poderiam ser criadas, por pessoas do movimento, empresas que canalizassem capacidades e recursos de todos para juntos produzirem riqueza, em prol dos que se encontravam em dificuldade. Sua gestão deveria ser confiada a pessoas competentes, capazes de fazê-las funcionar com eficácia e obter lucros (LUBICH, 2002, p. 15).

7 Costuma-se dizer que o projeto Economia de Comunhão se apresenta como uma experiência de liberdade, ou seja, é totalmente livre a participação de uma empresa ou pessoa neste projeto. As medidas a serem tomadas e a coerência com o projeto dependem do próprio indivíduo (ver BRUNI, 2002, p. 95). 
Vemos, então, que a proposta inicial de Chiara de criar empresas e polos produtivos e anos depois um movimento cultural que fornecesse "dignidade científica” à pratica das empresas dentro do sistema econômico vigente não caiu no vazio: ela foi acolhida por milhares de pessoas, na maioria dentro, mas, recentemente, também fora do Movimento dos Focolares; pessoas e instituições que estão tentando fazer frutificar aquela semente lançada há 22 anos.

De acordo com relatórios mais recentes da EdC, ${ }^{8}$ em outubro de 2012 havia 861 empresas das mais variadas dimensões: Europa, 501 (das quais 242 na Itália); América do Sul, 257; Estados Unidos e Canada, 35; Ásia; 25 e África, 43. Segundo o site oficial da EdC, nos últimos cinco anos 115 empresas decidiram aderir a esta ação econômica; 32 delas em 2012. Esta nova cultura econômica visa a apoiar um novo conceito do agir econômico, não apenas utilitarista, mas orientado para a promoção integral e solidária do homem e da sociedade. ${ }^{9}$ Também já foram realizadas diversas teses acadêmicas e artigos científicos que contribuem para a formação teórica de um projeto que nasceu da prática e da insatisfação empírica com a desigualdade.

Os dados têm evidenciado a capacidade da "coragem carismática" da EdC em enfrentar todos os desafios que têm-se levantado na economia no decorrer da história a essa proposta de um novo modelo econômico. Dessa forma vê-se a profecia de Chiara se configurar-se na história: dispor de condições para dar a sua contribuição ao bem comum dos homens e mulheres de hoje (e de amanhã), difundindo uma nova cultura econômica dentro e fora dos mercados.

\subsection{UMA NOVA CULTURA ECONÔMICA: EDC}

Assim como o capitalismo necessita para o seu crescimento da acumulação constante e crescente, a EdC necessita da formação e difusão de uma cultura que não seja pautada puramente pelos princípios capitalistas, mas que traga uma distinção primordial.

Segundo Ferrucci (1998) e Mulatero (2001), a EdC busca ser uma resposta pacífica aos desafios contemporâneos, especialmente no combate à pobreza, por meio da promoção de uma nova cultura, pautada no uso moderado e na partilha dos bens (materiais e não materiais). Os autores afirmam ainda que as empresas

8 Relatório Economia da Comunhão 2010/2011. Os dados sobre a destinação dos lucros, o censo das empresas no mundo, a cultura de comunhão e uma sondagem sobre a Identidade da EdC estão disponíveis na íntegra no site: <http://www.edc-online.org/br/quem-somos/partilha-dos-lucros/2186-il-rapporto-economia-di-comunione-20102011-e-online.html>. Acesso em: 5 dez. 2012.

9 Disponível em: <http://www.edc-online.org/br/quem-somos/a-difusao.html>. Acesso em: 5 dez. 2012. 
de EdC promovem a distribuição da riqueza por meio de doações monetárias, criação de empregos, investimento em projetos de expansão, compartilhamento de experiências e patentes entre as empresas que participam do projeto e financiamento para criação de novas empresas de EdC.

$\mathrm{Na}$ EdC a cultura da partilha se contrapõe ao individualismo e à competição, estruturando-se sobre relações baseadas em princípios de amor, solidariedade, gratuidade e unidade em busca da consolidação dos bens relacionais capazes de suportar as fragilidades do sistema econômico dominante. É nesse contexto que a EdC contribui com seu modus operandi pautado no respeito ao ser humano, colocando-o como centro da empresa. As firmas vinculadas à EdC "são empresas privadas, inseridas no mercado, que salvaguardam a propriedade particular dos bens, colocando o lucro em comunhão: uma visão humanista cristã do mundo dos negócios" (LEITÃO e SPINELLI, 2008, p. 453 apud LADAIN; COSTA; SALLES, 2012, p. 859).

Segundo Calliari (2000), a ideia inicial do projeto Economia de Comunhão, denominado antes de "Projeto Brasil", era ajudar os membros e simpatizantes do movimento que estavam em necessidades. Neste sentido, Chiara propôs a ideia de formar pessoas com capacidade de gestão que pudessem gerir empresas. Elas gerariam impostos para a região e o lucro seria partilhado em três partes: uma voltaria para a empresa na forma de reinvestimento, outra seria para a formação de "homens novos" e a última para ajudar os necessitados.

Chiara, ao deparar-se com a urgência de fazer algo para modificar aquela realidade, toma como exemplo aquilo que criou na Itália: o testemunho dos Focolares.

Naqueles primeiríssimos dias, a ideia delineou-se de modo mais preciso. O lucro das empresas deveria ser colocado em comum, mas destinado a três objetivos precisos: 1) para o desenvolvimento da empresa; 2) para a difusão da chamada "cultura da partilha” e da comunhão; 3) para os pobres, primeiramente para aqueles que frequentam as comunidades dos Focolares (BRUNI, 2011, p. 27).

A primeira parte é altamente necessária para a manutenção da empresa que vive no sistema capitalista e que precisa de recursos para operar, portanto, o reinvestimento se destina à compra de matérias-primas e manutenção de capital de giro capaz de atender as necessidades imprevistas da unidade produtiva.

A segunda parte destina-se à formação de "homens-novos". Compreende a formação de pessoas que possam ter esse carisma da unidade do Movimento Focolares, ou seja, essa parte do lucro serve para a difusão da Economia de Comunhão, de forma que o movimento possa ter cada vez mais adeptos dessa nova maneira de pensar a economia e a sociedade. Trata-se de desenvolver e espalhar por todo o mundo a chamada "cultura da partilha". 
A terceira parte consiste na preocupação que a EdC tem com os marginalizados pela sociedade, ou seja, aqueles que não possuem vida digna e que, algumas vezes, já perderam a esperança. Dessa forma, na empresa de Economia de Comunhão, os dirigentes e os funcionários conversam e escolhem uma comunidade pobre para então ajudar seus integrantes em suas necessidades. Essa é a parte principal do projeto, pois, de acordo com o site, ${ }^{10}$ ao longo desses vinte e dois anos de Economia de Comunhão, milhares de pessoas foram ajudadas.

É preciso ressaltar que a ajuda aos mais necessitados não precisa ser necessariamente financeira. O movimento não tem o objetivo de fazer filantropia. É algo que vai além disso. Segundo Bruni (2000), a proposta é fazer (re)nascer nessas pessoas a autoconfiança, a solidariedade e, consequentemente, uma melhor qualidade de vida. Nesse caso, a ajuda pode ser efetuada por meio de cursos de alfabetização, mutirão de casas, por exemplo. O objetivo é despertar na comunidade carente uma atividade econômica que possa suprir as necessidades dela. Enfim, não se trata de um assistencialismo e sim de mostrar para essas pessoas que elas são capazes de, por si mesmas, superar as suas dificuldades.

Nessa tentativa de responder aos desafios contemporâneos, Gui e Bruni (2001) afirmam que a EdC não entra em conflito com o capitalismo, visto como a própria distribuição dos lucros não é tida como algo revolucionário e novo. Para eles, o radicalismo da proposta encontra-se nos aspectos antropológico e cultural, ao se propor um modelo econômico pautado na comunhão, no amor, na gratuidade e na reciprocidade. Tais afirmações geram certa perplexidade: não é contraditório afirmar que uma proposta que introduz tais conceitos não entre em conflito com um modelo econômico pautado na acumulação, competição, instrumentalidade e individualismo como é o capitalismo?

A resposta é clara, pois a EdC não perde de foco a realidade econômica na qual está inserida. Ela vai ao encontro da principal finalidade do lucro de uma empresa capitalista, a saber: maximizar a riqueza dos acionistas, além das duas tradicionais destinações: distribuição para os acionistas e reinvestimento na empresa. A EdC pauta-se por uma nova forma de partilhar o lucro, uma das suas principais características.

Contudo, não se trabalha somente para a obtenção do lucro ou de salário. Como afirma Ferrucci (1992), o objetivo maior é mudar a mentalidade dos indivíduos que trabalham, fazendo crescer entre todos, dirigentes e operários, uma comunhão em todas as dimensões. Carvalho e Guareschi (2009) acrescentam que, para a EdC, a busca pelo lucro não deve ser vista como um fim em si mesmo ou como por objetivo apenas para o enriquecimento do empresário, mas como uma finalidade social, que deve ser gerado para depois ser distribuída pela sociedade.

10 Site: <http://www.edc-online.org/br/>. Acesso em: 5 dez. 2012. 
Nas empresas de Economia de Comunhão desenvolve-se a cultura de maximização das relações sociais e não de pura maximização do lucro como nas empresas puramente capitalistas ou guiadas por uma racionalidade utilitarista. $\mathrm{O}$ centro da empresa deve ser o homem. Portanto o objetivo de abrir empresas com o espírito de comunhão é exatamente fazer desenvolver-se naquele local e em outros uma relação entre as pessoas de forma que possa nascer e desenvolver-se entre elas a fraternidade.

Para alcançar este objetivo foi criado um movimento internacional, em formato de rede social envolvendo empresas que se comprometem a gerar nova riqueza: fundar postos de trabalho, com criatividade e inovação e partilhar seu lucro: uma parte para os mais pobres, outra para a promoção de "homens novos" que Lubich (2002) define como homens e mulheres que, formados em uma nova cultura, poderão contribuir para a realização de uma sociedade nova, renovada, mais justa e mais fraterna, que valorize a pessoa humana. Uma terceira parte é reinvestida na própria empresa.

Os sujeitos produtivos da economia de comunhão são empresários, trabalhadores, até mesmo clientes e fornecedores, e demais agentes empresariais, que buscam inspiração em princípios fundamentados em uma cultura diferente da prática e da teoria econômica vigente. Contudo, as empresas são a espinha dorsal do projeto. São instituições inseridas no mercado, que adotam as formas jurídicas comuns, mas que, por decisão livre dos seus titulares, se propõem a destinar os seus lucros de acordo com critérios ditados pelo bem comum.

Semelhate cultura pode ser definida como "cultura do dar" em antítese à "cultura do ter". O dar econômico é a expressão do "dar-se" no sentido de "ser". Em outras palavras, revela uma concepção antropológica que não é individualista nem coletivista, mas de comunhão. A “cultura do dar” que também não se confunde com filantropia nem com assistencialismo, virtudes de abordagem individualista. A essência da pessoa é estar em comunhão. Portanto, a EdC se caracteriza pela cultura de comunhão.

Bruni (2011b) argumenta que essa nova cultura de comunhão busca ser uma nova ordem econômico-social que repensa e liga duas realidades hoje opostas no capitalismo: a empresa e a pobreza. Em uma demonstração de economia com perfil da comunhão e, portanto, com perfil realmente humano.

De acordo com Lubich (2000), a visão religiosa também é um traço marcante do projeto. A Economia de Comunhão é, também, antes de tudo, um projeto inspirado da ética cristã. Essa visão religiosa é a que dá aos indivíduos o otimismo de que seus empreendimentos podem dar certo, principalmente, entre os dirigentes das empresas que acreditam na ação da Providência Divina em resolver alguns problemas como folha de pagamento ou encomendas inesperadas. Atribui-se a isso a presença de Deus na empresa. 
Essa atitude gera um ambiente de otimismo dentro da unidade produtiva. Por isso, Lubich cunhou na base da economia de comunhão vínculos antecedentes com o Evangelho a serem afirmados na prática pelos empresários, trabalhadores e membros da comissão de $\mathrm{EdC}$, que voluntariamente se integraram à proposta.

O quadro apresentado em seguida permite visualizar os fundamentos da economia clássica e da economia de comunhão. Alertamos que o quadro não tem caráter comparativo tendo em vista o estatuto de ciência que detém a primeira.

Quadro 8.1 - Fundamentos da Economia Clássica e da Economia de Comunhão

\section{Economia Clássica}

Adam Smith fundador da economia política clássica. Um homem.

Modo de produção capitalista.

A linha original de continuidade entre ética e economia é interrompida.

O individualismo na base das relações econômicas.

Cultura do ter.

A racionalidade consiste na utilidade, na acumulação e em elevar ao máximo o lucro privado.

Homo Economicus, Homo Consumérico individualista, hedonista, egoísta.

Oposição entre bem individual e bem social.

capital tem primazia em relação ao homem.

A relacionalidade incorpora sempre o elemento de condicionalidade.

Prevalência da racionalidade instrumental.

Racionalidade do eu.

Os indivíduos não estão ligados uns aos outros por nexos indivisíveis antes de iniciar a troca.

\section{Economia de Comunhão}

Chiara Lubich fundadora da economia de comunhão. Uma mulher.

Modo de produção de economia de comunhão.

A linha de originalidade entre ética e economia é retomada.

A solidariedade na base das relações econômicas.

Cultura do dar.

A racionalidade consiste na doação e partilha do lucro e pressupõe a personalização do relacionamento e a felicidade humana.

Homo doador. Solidário. Homo espiritual.

Sem oposição entre o bem individual e o bem social.

O homem tem primazia em relação ao capital.

A relacionalidade incorpora sempre $\circ$ elemento de gratuidade.

Prevalência da racionalidade substantiva, da razoabilidade que, segundo Aristóteles, contém elementos de sabedoria. Racionalidade do eu com todos.

Os indivíduos estão ligados uns aos outros por nexos indivisíveis antes de iniciar a troca. 
Quadro 8.1 - Fundamentos da Economia Clássica e da Economia de Comunhão (continuação)

\begin{tabular}{cc}
\hline Economia Clássica & Economia de Comunhão \\
\hline A cultura do ser para si. & A cultura do ser com o outro. \\
Apropriação privada do excedente. & $\begin{array}{c}\text { Apropriação privada do excedente e } \\
\text { partilhada com dois atores beneficiários } \\
\text { fora do processo produtivo. }\end{array}$ \\
Foco na avaliação. & Foco nos atores sociais. \\
Esquecimento da premissa antropológica. & Afirmação da premissa antropológica. \\
Empresa e sociedade. & Empresa na sociedade. \\
Isenção de valores religiosos. & Inclusão de valores religiosos. \\
\hline
\end{tabular}

Fonte: Gonçalves (2005, p. 83).

Esse modelo de economia, tendo em vista os muitos casos de sucesso, vem se apresentado como viável. Bruni (2011a) aponta alguns casos que exemplificam essa temática, haja vista que com a valorização do trabalho torna-se palpável uma interligação entre os setores organizacionais.

Há muitas experiências a esse proposito. Por exemplo, há uma empresa italiana cujos sócios, a fim de tornar visível a primazia da comunhão inclusive na organização da empresa, perceberam a exigência de institucionalizar uma reunião periódica com todos os componentes da empresa, de modo que, antes de serem dirigentes, ou trabalhadores, eles sentissem uma relação de reciprocidade (BRUNI, 2011a, p. 82).

Segundo Bruni (2000), a Economia de Comunhão faz nascerem, na Ciência Econômica, novas categorias que diferem de outras categorias já existentes dentro da Ciência. Uma delas é a categoria comunhão.

A categoria comunhão apresenta-se, portanto, como algo diferente da troca de equivalentes (de mercado). A doação, a reciprocidade e a solidariedade emergem, neste contexto, como categorias explicativas da Economia de Comunhão e, ao mesmo tempo, fornecem um paradigma de referência também para o mais amplo movimento da economia civil (BRUNI, 2000, p. 53-54).

Hoje este modelo de economia está presente em empresas de mais de 40 países dos cinco continentes, atuando em praticamente todos os ramos de atividades, produção, comércio, serviços, levando uma nova realidade para aqueles que aderem a este modelo econômico. Dentre estas empresas, algumas estão inseridas em Polos Industriais (ou produtivos). A ideia dos Polos Produtivos faz parte dos elementos básicos que compõem a primeira intuição da EdC. São concebidos como um laboratório visível e ponto de referência ideal e operativo também para as outras empresas do projeto. Existem polos empresariais na Argentina, na Itália, na Croácia, na Bélgica e no Brasil. 
O Brasil, pioneiro do projeto, já apresenta mais de 140 empresas de Economia de Comunhão e três polos industriais: o polo Ginetta, no Recife (PE), François Neveux, em Belém (PA), Spartaco, em Cotia (SP), a $50 \mathrm{~km}$ da capital. Esses polos podem ser considerados como embriões de solidariedade e fraternidade aplicados ao modelo de gestão empresarial cuja centralidade é a cultura da partilha dentro e fora da empresa.

Há vários relatos que atestam ser eficaz e viável à Economia da Comunhão. Eis um deles:

Uma empresária das Filipinas explicava porque a empresa de consultoria que ela fundara para participar do projeto, largando seu emprego num banco, tornara-se, em cinco anos, a mais importante do Sudoeste da Ásia no seu setor: "Deus nos ajuda porque temos muitos irmãos carentes a ajudar, crianças que, se não forem tratadas logo, ficarão cegas” (BRUNI, 2002, p. 39).

A cultura da partilha é a cultura da doação, não um doar contaminado pelo poder, pelo assistencialismo, pelo utilitarismo, pelo interesse privado, mas um doar gratuito sem a expectativa de retribuição; nele as relações humanas são vividas como dom e não esperam retribuição. Porém, há que se manifestar os conceitos de reciprocidade e as estruturas de comunhão. Uma gratuidade de valores e de dons pessoais e não somente materiais (ARAÚJO, 2001).

Com essa visão muitas empresas estão mudando o paradigma dominante e a ideologia produtivista que lhe dá sustentação ao se orientarem para uma forma de economia solidária, de partilha. Essas empresas trazem em sua bagagem conceitual o germe da mudança. Talvez o mais importante neles seja estarem demonstrando o quanto pode ser feito quando se tem vontade política para fazê-lo, diferenciando-se o que é factível da utopia a partir de uma motivação de origem espiritual.

Uma vez que as empresas de Economia de Comunhão não buscam apenas o lucro, mas também um crescimento sustentável, que considere igualmente o meio ambiente, seus funcionários e pessoas necessitadas da comunidade em que está inserida. Os efeitos positivos se estendem para fora de seus limites empresariais. O movimento de EdC pode adquirir assim dimensões de fenômeno social. Porém, ao contrário de organizações filantrópicas ou assistenciais, que atuam somente como iniciativas de cunho social, a Economia de Comunhão é uma tentativa de inserir o social no cerneda economia (SORGI, 1998, p. 34).

\subsection{EDC E EÇONOMIA SOLIDÁRIA: UMA DISTINC̣ÃO NECESSÁRIA}

Observa-se desde o final do século XX e início do século XXI uma série de mudanças que as relações econômicas, especialmente as relações de trabalho, vêm 
sofrendo, mas que não chegam a superar o modo de produção capitalista que continua central.

Carvalho e Guareschi (2009) afirmam que, nesse cenário, para legitimar e garantir a reprodução das relações básicas de produção capitalistas, novas construções sociais, ideológicas, políticas e religiosas (dentre outras) estão surgindo. Nesse contexto, apresentam-se iniciativas que surgiram na sociedade a partir do século passado. Iniciativas que têm no princípio da solidariedade a força motriz de sua implementação. Dentro dessa perspectiva, dois modelos merecem ser discutidos e diferenciados: o da EdC, cujo estudo é objeto deste trabalho e o da Economia Solidária (ES).

A EdC oferece possibilidades para enfrentar os desafios que a atualidade impõe à sociedade. Em conjunturas como essa é esperado que surjam alternativas para conceber a economia de um modo diferente. A EdC também propõe uma maneira de reagir à situação atual de mal-estar e aridez da economia capitalista, fundamentando-se no princípio da solidariedade.

Neste sentido, a EdC mostra-se como uma filosofia empresarial que se materializa no modo de gestão, cujas relações internas e externas se dão de modo a atuar a partilha, a ética e o respeito frente aos agentes relacionados à empresa. Como foi explanado em outro momento, ela nasce no Brasil, em 1991, por inspiração de uma italiana e, a partir de então, é adotada por empresários brasileiros e de diversos outros países que se identificaram com a proposta. O que ela propõe, todavia, é uma nova mentalidade de gestão que pode fazer o meio empresarial perder sua característica típica de acumulação para evidenciar outras práticas, como a da comunhão, necessárias nos dias atuais.

Para realizar esta proposta, a EdC investe na atividade laboral e se estrutura com base na economia moderna. Além disso, orienta-se no sentido de colocar em comum os recursos disponíveis, revitalizados por homens dispostos a viver o princípio da solidariedade, abertos ao exterior em direção a uma economia a serviço da comunidade local e mundial.

A EdC vai além da proposta da comunhão de bens porque se trata da vivência dessa comunhão; não se limita mais a doá-los simplesmente, mas esses bens são colocados em circulação na sociedade para que outros produzam com ele. Ela propõe a expressão econômica de uma vida de comunhão concretizada nas relações econômicas entre homens que doam livremente em função do bem comum, os talentos, as capacidades empresariais, o profissionalismo ou o próprio dinheiro.

A Economia Solidária, por sua vez, apresenta-se como um conceito ainda em construção, divergente entre alguns autores ou interpretado de forma diferenciada, podendo abranger um numeroso leque de atividades. Essa falta de coesão de seu conceito, todavia, é vista como algo positivo por ser a ES um ato de vontade 
no sentido de construir uma sociedade melhor do que a que vem se apresentando. Assim é que Paul Singer (2005) entende a multiplicidade de conceitos em torno da Economia Solidária como algo positivo, uma riqueza para a própria conceituação. Diz ele:

Temos o direito de conceber a Economia Solidária de acordo com nossos princípios e de acordo com nossos valores. Por isso que há tantas concepções diferentes de Economia Solidária. Eu acho essa diferença desejável. Eu acharia uma perda se nós nos colocássemos agora em acordo e disséssemos "Economia Solidária é isso e quem não achar isso está errado" (SINGER, 2005, p. 11).

Singer (2002) sustenta que a Economia Solidária surgiu como modo de produção e distribuição alternativo ao capitalismo, criada e recriada periodicamente pelos que se encontram (ou temem ficar) marginalizados do mercado de trabalho. Para Singer (2002) e Santos (2002), o início da Economia Solidária é contemporâneo do capitalismo industrial na Grã-Bretanha, recebendo influência dos socialistas utópicos, como Owen, justamente em função da onda de desemprego que a industrialização causou na época. Este autor e alguns outros, portanto, fazem referência às origens da ES como sendo coincidentes com a origem do cooperativismo.

Alguns autores relacionam a ES com o cooperativismo, remetendo-a para o início do ano de 1844 com os chamados Pioneiros de Rochdale - 28 tecelões de uma pequena cidade da Inglaterra chamada Rochdale -, os quais se juntaram e formaram uma sociedade cooperativa, também embasada no pensamento dos chamados socialistas utópicos, entre eles Robert Owen. ${ }^{11}$

A unidade característica da Economia Solidária é a cooperativa de produção, cujos princípios organizativos são: posse coletiva dos meios de produção por parte das pessoas que os utilizam para produzir; gestão democrática da empresa ou por participação direta (quando o número de cooperados não é grande) ou por representação, repartição da receita líquida entre os cooperados por critérios aprovados após discussões e negociações entre todos; destinação do excedente anual (denominado "sobras") também por critérios acertados entre todos os cooperadores.

11 Em meio à exploração dos trabalhadores pelos industriais, comum na época, entre os próprios industriais destacaram-se alguns que tiveram uma visão diferenciada do modo de se relacionar com os trabalhadores, como Robert Owen. Ele decidiu limitar a jornada de trabalho de seus operários e passou a não aceitar crianças trabalhando; ao invés disso as incentivou a estudar. Esse modo de gerir sua indústria lhe trouxe também maior lucratividade, pois aumentou a produtividade. Owen se transformou em um dos mais importantes socialistas utópicos mediante a criação de várias comunidades industriais. Fonte: Brasil Escola <www.brasilescola.uol.com. br>. Acesso em: 5 dez. 2012. 
Havendo nascido em um contexto europeu de condições de trabalho precárias, o seu início no Brasil deu-se na década de 1980, desenvolvendo-se de modo mais expressivo a partir da década de 1990.

A ES conquistou o interesse de estudiosos, do poder público e da sociedade civil, mostrando-se hoje ao país de maneira mais articulada por meio, inclusive, de uma Secretaria dentro do Ministério do Trabalho e Emprego (MTE), a Secretaria Nacional de Economia Solidária (SENAES). Ela objetiva, por meio de modos de organização de produção e de consumo diferenciados, criar alternativas de melhores condições de vida, sobretudo para pessoas que se encontram à margem do sistema. Funciona assim como solução alternativa para o desemprego.

A EdC e a ES são duas propostas de cunho social e empresarial ao mesmo tempo, que buscam a promoção do ser humano. Por terem objetivos semelhantes, assim como seus próprios nomes que sugerem algo voltado para o social, a clareza a respeito de cada uma dessas iniciativas muitas vezes é comprometida no meio acadêmico.

A partir da visão de Singer (2005), seria possível afirmar que a EdC estaria inserida no contexto da ES, dada a flexibilidade do conceito de ES que o autor propõe. Todavia, o conhecimento das duas iniciativas leva a uma análise diferenciada; afinal, academicamente falando, essa singularidade dos termos e do que eles significam tem também a sua relevância.

Chiara, quando lançou a EdC, certamente não estava pensando em movimento datado anteriormente pela experiência dos Pioneiros de Rochdale $;^{12} \mathrm{em}$ vez disso, a EdC nasceu da realidade brasileira dos anos 1990, que, inclusive, se assemelha em grande parte com aquela presente nas origens da ES.

A Economia de Comunhão, por tudo o que já foi visto a seu respeito, tem sua origem igual e distinta da ES ao mesmo tempo. Igual porque foi inspirada pela situação de pobreza presente no Brasil, mesma problemática da Inglaterra na época, onde essa mesma situação se apresentava nas duras condições de trabalho às quais se submetiam os trabalhadores. Distinta porque nasceu de dentro de uma comunidade, com uma filosofia própria que inspirou a comunhão já vivida internamente nessa comunidade no sentido de estender-se ao meio empresarial.

Além disso, a forma do próprio empreendimento é distinta, uma vez que na ES encontram-se o cooperativismo e a autogestão como algumas de suas princi-

12 Apesar de Singer remeter a origem da ES à Owen e aos demais autores denominados socialistas utópicos, ele vê a ES como sendo não o fruto da criação intelectual de alguém. Segundo Singer (2003a, p. 13) "a Economia Solidária é uma criação em processo contínuo de trabalhadores contra o capitalismo". O que a ES condena no capitalismo, na visão do autor, é a ditadura do capital da empresa que dá ao empresário o direito de tomar atitudes segundo sua vontade mesmo em detrimento do trabalhador e de seu emprego. De fato, “a empresa solidária nega a separação entre trabalho e posse dos meios de produção, que é reconhecidamente a base do capitalismo” (SANTOS, 2002, p. 83). 
pais características. A EdC, por outro lado, tem como base a empresa capitalista. Nela é o proprietário dos meios de produção que tem a oportunidade de fazer algo, enquanto na ES são os próprios trabalhadores que se organizam entre si. Enquanto a EdC propõe um modelo alternativo de gestão, a ES propõe um modelo alternativo de organização da produção.

\begin{abstract}
Algo a ser colocado em evidência é que a EdC e a ES, entre tantas outras iniciativas, são, cada uma a seu modo e segundo seus próprios princípios, formas alternativas que nossa conjuntura vem forçando a existir, ou seja, o país passa por um momento em que a sociedade civil se encontra no papel de pressionar o poder público e de fazer ela mesma a sua parte para buscar formas alternativas de gestão e produção, que propiciem às pessoas recuperar, em última instância, sua condição de cidadão (MARTINS et al. 2006. p. 12).
\end{abstract}

Nesse sentido, surge a seguinte questão: uma empresa de Economia Solidária não é também uma empresa de Economia de Comunhão e vice-versa? Até que ponto um modelo não contém também o outro?

Segundo Bruni (2005), a Economia Solidária traz à tona um novo formato de empresas, como o caso das cooperativas, que se caracterizam, principalmente, pelo fato de não terem fins lucrativos. A Economia de Comunhão por sua vez não propõe novas formas de empresas, mas uma nova cultura que estimula a comunhão entre as pessoas na organização. Na saída do processo, o lucro gerado - perpetuando a perspectiva de comunhão, que não se limita à organização - é colocado em comum com aqueles que não conseguem suprir suas necessidades materiais e uma parte contribui com a difusão desta proposta em favor do bem comum e da formação de "homens novos". Bruni acrescenta que se a comunhão não se tornar cultura não haverá qualquer esperança de a EdC durar no tempo.

Como se pode ver, a Economia Solidária e a Economia de Comunhão nasceram da identificação e necessidade de resolver o problema social, mas com estrutura e perspectivas diferentes. Assim, as compreensões das especificidades, o alcance de cada uma dessas iniciativas e a distinção de seus conceitos podem assegurar a importância de cada uma e, sobretudo, oferecer melhor compreensão da própria EdC. Todavia, é importante acrescentar que o objetivo não é de estabelecer qualquer tipo de hierarquia da Economia de Comunhão, mas compreender melhor o tema proposto a fim de poder contribuir para sua difusão e desenvolvimento.

\title{
8.6 CONSIDERAC̣ÕES FINAIS
}

$\mathrm{Na}$ EdC não se modificam as características e os princípios do capitalismo, mas renova-se sua dimensão cultural para descobrir a verdade integral sobre o homem e permitir assim se relacionar com o mesmo dinamismo econômico, 
porém com uma ética autenticamente humana que respeite a dignidade e liberdade do homem. Sendo a economia uma ciência social, uma aproximação às questões éticas é de todo inevitável pelos teóricos da economia.

Sen (2006), por exemplo, afirma que o empobrecimento das teorias econômicas modernas se dá devido ao distanciamento entre economia e ética. A EdC instiga esse debate ao reintroduzir a ética nas relações de produção, distribuição e consumo, retomada por muitos economistas, fornecendo hoje para a Teoria Econômica a capacidade de exercer as atividades que são pertinentes à Economia no que tange à produção de bens em um ambiente ético e harmônico, mostrando que é possível conciliar crescimento econômico e empresarial com ética e solidariedade.

\section{REFERÊNCIAS}

ARAÚJO, Vera. Qual homem e qual sociedade para a economia de comunhão? Abba, São Paulo, v. 4, n. 3, p. 39-48, 2001.

ASSOCIAÇÃO NACIONAL POR UMA ECONOMIA DE COMUNHÃO. Disponível em: <http://anpec-edc.com.br/>. Acesso em: 20 set. 2012.

BERTUCCI, Ademar et al. Economia solidária: uma outra economia a serviço da vida acontece. Brasília, DF: Fórum Brasileiro de Economia Solidária, 2010.

BRUNI, Luigino. Comunhão e as novas palavras em economia. São Paulo: Cidade Nova, 2011a.

. Desafios e perspectivas: folder economia de comunhão. São Paulo, 2011b. 1 folder. . Economia de comunhão: uma cultura econômica em várias dimensões. São Paulo: Cidade Nova, 2002.

. Para uma Teoria Econômica de Comunhão. In: BUREAU INTERNACIONAL DA ECONOMIA E TRABAlHO, 2000, São Paulo. Anais... São Paulo: Cidade Nova, 2000.

CARVALHO, Maria Luiza; GUARESCHI, Pedrinho. Economia de comunhão: responsabilidade social, ideologia e representações sociais. Psicologia Ciência e Profissão, Brasília, DF, v. 29, n. 1, p. 88-101, 2009. Disponível em: <http://www.scielo. br/pdf/ pcp/v29n1/v29n1a08.pdf>. Acesso em: 20 abr. 2013.

ECONOMIA DE COMUNHÃO. Site oficial da EdC. Disponível em: <http://edc-online. org/br>. Acesso em: 1 set. 2012.

FERRUCCI, Alberto. Considerações sobre a economia de comunhão. In: COSTA, Rui et al. Economia de comunhão: projeto, reflexões e propostas para uma cultura da partilha. 2. ed. São Paulo: Cidade Nova, 1998, p. 69-92.

. Considerações sobre a economia de comunhão. In: QUARTANA, Pino.

Economia de Comunhão. São Paulo: Cidade Nova, 1992.

GONÇALVES, Heloisa Helena A. Borges Q. A experiência dos pioneiros da economia de comunhão na liberdade no primeiro decênio (1991-2001) no Brasil: absurdo e 
graça da mudança de mentalidade do empresário. 2005. 348 p. Tese (Doutorado em Ciências de Engenharia de Produção) - Coppe - Instituto Alberto Luiz Coimbra de PósGraduação e Pesquisa de Engenharia, da Universidade Federal do Rio de Janeiro. Rio de Janeiro, 2005.

LADAIN, Maria Célia Vieira; COSTA, Isabel de Sá Affonso da; SALLES, Denise Medeiros Ribeiro. As práticas de gestão de pessoas nas empresas de economia de comunhão: estudo de caso no Polo Spartaco. Cad. EBAPE.BR, Rio de Janeiro, v. 10, n. 4, p.858-882, dez. 2012.

LUBICH, Chiara. O Movimento dos Focolares e a Economia de Comunhão. In: BUREAU INTERNACIONAL DA ECONOMIA E TRABALHO, 2000, São Paulo. Anais... São Paulo: Cidade Nova, 2000.

. Economia de Comunhão: história e profecia. São Paulo: Cidade Nova, 2004. MOVIMENTO DOS FOCOLARES. Site oficial brasileiro. Disponível em: <http:// focolares.org.br/sitenacional/>. Acesso em: 30 set. 2012.

MARTINS, Cláudia Herrero; CRUCIAL, Cristiane Vercesi; ARAÚJO, Evandro José da Cruz. Economia e comunhão e economia solidária: uma distinção de conceitos. In: Encontro da ANPAD, 30., 2006, Salvador. Anais eletrônicos... Salvador: ANPAD, 2006. Disponível em: <http://www.anpad.org.br/enanpad/2006/dwn/enanpad2006-apsc-0853. pdf $>$. Acesso em: 5 maio 2013.

MULATERO, Caterina. Os pobres, "atores" do projeto de EdC. Economia de Comunhão: uma nova cultura, Vargem Grande Paulista, v. 13, n. 1, p. 12. jun. 2001. Suplemento.

QUARTANA, Pino. A economia de comunhão no pensamento de Chiara Lubich. In: Economia de Comunhão. São Paulo: Cidade Nova, 1992.

SANTOS, Boaventura de Souza (Org.). Produzir para viver: os caminhos da produção não capitalista. Rio de Janeiro: Civilização Brasileira, 2002.

SEN, Amartya. Sobre ética e economia. São Paulo: Companhia das Letras, 1999. SINGER, Paul. Introdução à economia solidária. São Paulo: Fundação Perseu Abramo, 2002.

. Economia solidária: um modo de produção e distribuição. In: SINGER, Paul; SOUZA, André Ricardo de (Org.). Economia Solidária no Brasil: a autogestão como proposta ao desemprego. 2. ed. São Paulo: Contexto, 2003. p. 11-28.

. Introdução. In: MELLO, Sylvia Leser de (Org.). Economia Solidária e autogestão: encontros internacionais. São Paulo: NESOL-USP, 2005. p. 9-16. SORGI, Tammaso. A cultura do dar. In: COSTA, Rui, et al. Economia de comunhão: projeto, reflexões e propostas para uma cultura da partilha. 2. ed. São Paulo: Cidade Nova, 1998. p. 31-68.

SPOSATI, Aldaíza. Globalização: um novo e velho processo. In: DOWBOR, Landislau et al. (Org.). Desafios da Globalização. Petrópolis: Vozes, 1997. p. 43-49. 
